\title{
Understanding the inflammation-cancer transformation in the development of primary liver cancer
}

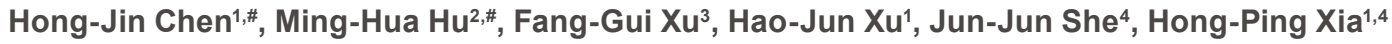 \\ 'Department of Pathology, School of Basic Medical Sciences \& The Affiliated Sir Run Run Hospital, Nanjing Medical University, \\ Nanjing 21116, China. \\ 2Department of Hepatobiliary Surgery, The Affiliated Yijishan Hospital of Wannan Medical College, Wuhu 241001, China. \\ ${ }^{3}$ Department of General Surgery, The Affiliated Sir Run Run Hospital, Nanjing Medical University, Nanjing 21116, China. \\ ${ }^{4}$ Department of General Surgery, The First Affiliated Hospital of Xi'an Jiaotong University, Xi'an 710061, China. \\ \#Authors contribute equally to this work.
}

Correspondence to: Dr. Hong-Ping Xia, Department of Pathology, School of Basic Medical Sciences \& The Affiliated Sir Run Run Hospital, Nanjing Medical University, Nanjing 21116, China. E-mail: xiahongping@njmu.edu.cn; Dr. Jun-Jun She, Department of General Surgery, The First Affiliated Hospital of Xi'an Jiaotong University, Xi'an 710061, China. E-mail: sjuns@sina.com

How to cite this article: Chen HJ, Hu MH, Xu FG, Xu HJ, She JJ, Xia HP. Understanding the inflammation-cancer transformation in the development of primary liver cancer. Hepatoma Res 2018;4:29. http://dx.doi.org/10.20517/2394-5079.2018.18

Received: 12 Mar 2018 First Decision: 10 May 2018 Revised: 11 Jun 2018 Accepted: 11 Jun 2018 Published: 5 Jul 2018

Science Editor: Guang-Wen Cao Copy Editor: Jun-Yao Li Production Editor: Cai-Hong Wang

\begin{abstract}
Primary liver cancer is one of the leading causes of cancer-related deaths worldwide. China has more than 55\% liver cancer cases globally. The development of hepatocellular carcinoma (HCC) was caused by a variety of risks factors, including chronic inflammation by virus, alcohol consumption and non-alcoholic steatohepatitis. Emerging evidence has notarized inflammation as a critical component of $\mathrm{HCC}$ progression. The development of $\mathrm{HCC}$ is a multistep process which may originate from liver chronic injury and inflammation to subsequent fibrosis and/or cirrhosis and finally HCC. A large number of studies indicate that chemokines and cytokines are candidates linking molecules between inflammation and liver cancer. Here, we will describe a few of the key cytokines and chemokines and signal pathways which are involved in the inflammation of HCC. Inhibitors of inflammation for the prevention and overcoming antitumor immunity for treatment of liver cancer are promising candidates for the future management of patients with HCC.
\end{abstract}

Keywords: Inflammation, liver cancer, cytokines, chemokines, signaling pathways

\section{INTRODUCTION}

Primary liver cancer is one of the leading causes of cancer-related deaths and the fifth common largest tumor type worldwide (http://globocan.iarc.fr). It can be categorized into hepatocellular carcinoma (HCC),

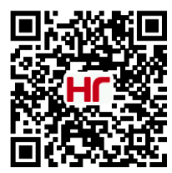




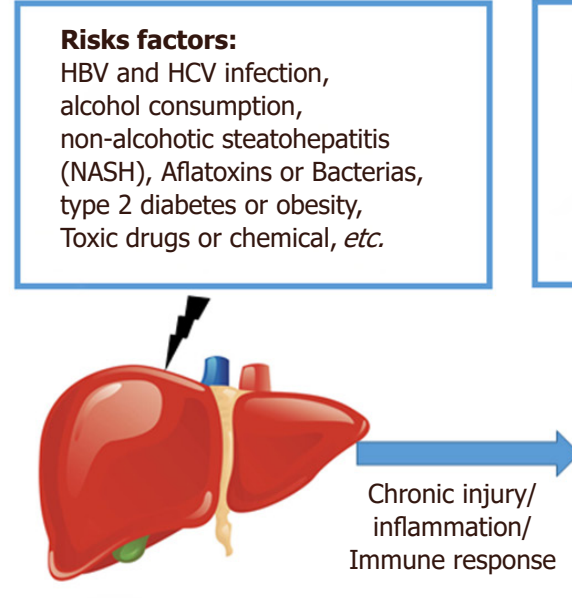

Normal liver

\section{Inflammation cytokines and} chemokines:

TNF- $\alpha$, IL-6, IL-1 $\beta$, IL-10, COX-2, VEGF, HIF- $1 \alpha$, MMPS, Erk, Akt, TGF- $\alpha / \beta 1$, JNK, ERK, P38, ELK-1, AP-1, TCF, CD95, IL-1 1 , I $\mathrm{B}, \mathrm{TRAF}-1 / 2, \mathrm{NF}-\kappa \mathrm{B}$, etc.

Figure 1. The multistep process of the development of liver cancer. The risk factors, inflammation cytokines and chemokines, and hepatocarcinogenic pathways are related to the inflammation-cancer transformation during the development of primary liver cancer

intrahepatic cholangiocarcinoma (iCCA), and other rare types such as hepatoblastoma and fibrolamellar carcinoma according to the pathological type. Tumor morphology can be divided into nodular, massive and diffuse types of liver cancer ${ }^{[1]}$. It's worth noting that more than 500,000 people receive a diagnosis of HCC every year and the incidence is still increasing worldwide, by about $4 \%$ per year in men and $3 \%$ per year in women ${ }^{[2]}$. The number of fatal cases accounts for about $5.4 \%$ of all malignancies each year globally. It is estimated that there will be over 1 million new cancer diagnoses of HCC each year by $2025^{[3]}$. China has more than 55\% liver cancer cases globally. HCC accounts for approximately $90 \%$ of primary liver cancer ${ }^{[4]}$. Currently, it is very limited for HCC patients to choose the suitable treatment. Over the past 2 decades, the median survival time for advanced HCC patients is less than 1 year, and the 5-year relative survival rate is below $9 \%{ }^{[4]}$. Patients with well-preserved liver function will select surgical resection. The most effective way for HCC patients to improve the survival is liver transplantation. Unfortunately, those treatments often result in a poor prognosis, including a high risk of postoperative complications and recurrence of the tumor. Although there are various strategies, such as liver transplantation, surgical resection, target drugs (sorafenib, lenvatinib or regorafenib) and immunotherapy (nivolumab), to extend survival time of liver cancer patients, those treatments are not effective ${ }^{[5]}$. It has been well recognized that HCC is a complex and heterogeneous malignancy, caused by a variety of risks factors, including chronic inflammation by virus, like hepatitis B virus (HBV) and hepatitis $\mathrm{C}$ virus (HCV), alcohol consumption, non-alcoholic steatohepatitis (NASH), bacteria, type 2 diabetes, smoking or chemical. Age and gender are also risk factors for HCC ${ }^{[6]}$. HCC is more common in middle-aged men with a male to female ratio of up to (3-8):1. In China, the major component of the attributable risk is chronic hepatitis $\mathrm{B}^{[7]}$. Based on those different causes, the molecular pathogenesis of HCC is very complicated. This review is intended to facilitate the understanding of the risk factors, inflammation cytokines and hepatocarcinogenic pathways related to the inflammation-cancer transformation during the development of primary liver cancer [Figure 1].

\section{INFLAMMATION AND LIVER CANCER}

Virchow postulated the connection between cancer and inflammation in $1863^{[8]}$. It has been estimated that inflammation and chronic infection would lead to the development of about $15 \%$ human cancers ${ }^{[9]}$. A large number of epidemiological investigations suggest that inflammation is one of the main factors leading to tumorigenesis or promoting tumor development ${ }^{[10]}$. Recently, more and more data have notarized inflammation as a critical component of HCC progression. Direct evidences suggesting chronic inflammation, especially hepatitis B and hepatitis C, are the risk factor for HCC. Patients who have those diseases will get more risk to 
develop HCC ${ }^{[1]}$. The development of HCC is a multistep process. There is a common situation that HCC are originating from liver chronic injuries and inflammation, subsequent fibrosis and/or cirrhosis. When patients get liver injury or inflammation, the liver parenchymal cells will die and release signaling molecules of death, or cause inflammatory reaction. During chronic inflammatory hepatitis, the host's immune response to $\mathrm{HBV}$ or HCV is usually not strong enough to eradicate the infection and damage, eventually leading to the body's continued over-activation ${ }^{[12-14]}$. Cirrhosis is a chronic, progressive diffuse change in the liver caused by a variety of factors. Long-term damage to liver cells will lead to degeneration and necrosis of liver cells. After a wide range of liver cell degeneration and necrosis, intrahepatic connective tissue is regenerating, then fibrous tissue is diffusing proliferation. This process helps promote the development and progression of liver cancer. The process involved many mechanisms such as oxidative stress, endoplasmic reticulum stress and mitochondrial damage, which will activate and promote the synthesis and secretion of tumor-related transcription factors and cytokines, resulting in DNA damage and further promoting tumorigenesis ${ }^{[15-18]}$.

\section{INFLAMMATORY SIGNALING PATHWAYS OF HCC}

The relationship between liver inflammation and HCC is strongly suggested by recent studies. A lot of evidences about inflammatory mediators and signaling pathways are reported in $\mathrm{HCC}^{[4,9,19]}$. However, there is a lack of adequate clinical evidence to support the routine use of anti-inflammatory drugs to improve the prognosis of patients with liver cancer. So it is an interesting strategy to further investigate the antiinflammatory treatment for liver cancer. A large number of studies indicated that chemokines and cytokines are candidates linking molecules between inflammation and cancer. The following parts will describe a few of the key cytokines and chemokines and signaling pathways which are involved in the inflammation and HCC.

\section{Cytokines and chemokines}

Inflammatory cytokines are critically important in the liver injury development. When liver tissue or cells stimulate with stimulants like alcohol and fatty acid, liver tissue synthesizes various types of cytokines to defend that ${ }^{[20-25]}$. The well-studied cytokines include tumor necrosis factor- $\alpha(\text { TNF- } \alpha)^{[26,27]}$, interleukin family (IL-6, IL-1 $\beta)^{[7,28,29]}$, chemokines (VCAM-1, ICAM-1 and MCP-1 ${ }^{[30-33]}$, etc. TNF- $\alpha$ and IL- 6 are two multifunctional cytokines in chronic hepatic inflammation. Kuffer cells will be activated during chronic hepatitis, including NASH, alcoholic hepatitis, and hepatic infections with HBV and HCV, and inflammatory cytokines. Following that, TNF- $\alpha$ and IL- 6 will be synthesized and secreted in abundance. Elevated serum levels of TNF- $\alpha$ and IL- 6 have been found in patients with chronic hepatitis $\mathrm{B}^{[34,35]}$. Higher serum levels of TNF- $\alpha$ and IL- 6 have been reported as the high risk factors for cirrhosis and HCC development in patients, especially with HBV and HCV infection. Several studies have shown that the hepatic tissue of DEN-treated rats or mice has increased IL- 6 and TNF- $\alpha$ production levels compared with the control group ${ }^{[36]}$. It has been certified that TNF- $\alpha$ causes DNA damage through the induction of reactive oxygen species (ROS) ${ }^{[19,37]}$. IL-6 and IL-1 $\beta$ can potentially promote autophagy in liver tumor cells ${ }^{[25,38]}$. IL-1 $\beta$ has been linked with inflammasome NLRP3 to promote the occurrence and development of chronic liver disease ${ }^{[39]}$. Both IL-1 $\beta$ and TNF- $\alpha$ are related to stimulate cancer cell proliferation during chronic inflammation situation ${ }^{[40]}$.

Chemokines induce chemotactic migration of targeting cells through their interaction with their receptors. A large number of studies have shown that chemokines are up-regulated in various liver injuries. In chronic liver inflammation, inflammatory factors, growth factors, oxygen stress and their products stimulate the expression of chemokines. High expression of chemokines can activate hepatic stellate cells (HSC) involved in the formation of liver fibrosis and even cirrhosis. It should been noted that IL-1 $\beta$ and TNF- $\alpha$ can activate quiescent HSC to produce MCP-1, IL-8, indicating that inflammatory cytokines further accelerate the conversion of inflammation to cancer through chemokines ${ }^{[11-43]}$. The CXC family is a family of chemokines that have attracted the most attention during the metastasis of cancer and this family can promote the migration of neutrophils, which often promote the development of inflammation. CXCL1, CXCL2, CXCL3 and CXCL have been reported to be highly expressed in hepatoma cells ${ }^{[44,45]}$. It has been shown that CXCL12 
activates expression of matrix metalloproteinase 10, which further stimulates migration of HCC cells ${ }^{[46]}$. In summary, these evidences showed that inflammation contributes to cancer by supplying important and various molecules to the tumor microenvironment.

\section{Signaling pathways}

\section{PI3K/AKT/mTOR pathway}

In 1993, Kisen et al.$^{[4]}$ observed the existence of autophagy in pre-cancerous hepatocytes induced by chemical carcinogens in rats, and proposed a new target that could potentially be used to treat HCC. Autophagy has the dual role of promoting and inhibiting the evolution of liver cancer ${ }^{[48,49]}$. Autophagy often occurs in the reduction from the pre-cancer stage to the occurrence of cancer and the reduction of autophagy can lessen tumor cell autophagic death, so it plays a facilitating role in the growth of the tumor. However, before the formation of blood vessels, the tumor cells are in a state of low nutrition and hypoxia, which stimulate autophagy through the PI3K/AKt/mTOR pathway. Enhanced autophagy can provide nutrients to the hungry tumor cells by removing damaged proteins, organelles and macromolecules, thereby inhibiting apoptosis of tumor cell. The PI3K/AKt/mTOR pathway is of great importance to the development, progression and treatment of HCC. It has been reported that TNF- $\alpha$ and IL- 6 induced VEGF expression and angiogenesis can be significantly inhibited by rapamycin, indicating that mTOR plays an important role in inflammationinduced angiogenesis ${ }^{[50]}$. Inflammatory factors such as TNF- $\alpha$, IL-6, IL-1 $\beta$ and other secretions are also regulated by mTOR signaling pathway ${ }^{[51]}$. In the case of sustained activation of the mTORC1 pathway, the expression of pro-inflammatory cytokines such as IL-6, TNF- $\alpha$ are decreased and the expression of the antiinflammatory cytokine IL-10 is increased ${ }^{[52]}$.

The role of PI3K/AKt/mTOR pathway in HCC can be summarized as follows: (1) promoting the formation of tumor blood vessels: PI3K/AKt/mTOR pathway participates in the formation of blood vessels in tumor mainly through two ways: PI3K/AKt signaling pathway can activate the cyclooxygenase 2 (COX-2), which is a key enzyme that catalyzes the synthesis of prostaglandin-like substances, thereby promoting the angiogenesis of liver cancer $^{[53]}$. Hypoxia and growth factors can induce the expression of hypoxia inducible factor $1 \alpha(\mathrm{HIF}-1 \alpha)^{[54]}$, the downstream blood vessels endothelial growth factor (VEGF) transcription ${ }^{[55]}$. The PI3K/AKt pathway activation can up-regulate the expression of HIF-1 $\alpha$ and VEGF, thus making endothelial cell migrate to form new blood vessels; (2) promoting tumor invasion and metastasis: Johnson and Tee ${ }^{[56]}$ have shown that PI3K/ $\mathrm{AKt} / \mathrm{mTOR}$ activation can make the downstream molecules p70s6k phosphorylated to make actin filament remodel and to enhance the ability of tumor cells to move, thus increasing the invasion and metastasis of cancer cells. Activation of Akt increases the transcriptional activity of NF- $\kappa B$ and the motor function of tumor cells, which facilitates invasion of cancer cells ${ }^{[57]}$. The PI3K/AKt/mTOR pathway can up-regulate the expression of matrix metalloproteinase $2(\mathrm{MMP}-2) \mathrm{mRNA}$ and protein, and degrade the extracellular matrix (ECM) to promote tumor cell metastasis ${ }^{[58]}$; (3) promoting cell cycle progression: studies show that the PI3K/AKt/mTOR signaling pathway can transmit mitotic signals to p70s6k, and p70s6k can up-regulate major cell cycle proteins such as cyclin and $\mathrm{CDK} 4^{[59]}$, while increasing the expression of CDK4 accelerates the cell cycle progression, thereby promoting cell proliferation and differentiation which both result in liver cancer ${ }^{[0]}$. Unfortunately, the EVOLVE-1 randomized clinical trial showed that the MTOR inhibitor, everolimus, did not improve overall survival in patients with advanced HCC whose disease progressed during or after receiving sorafenib or who were intolerant of sorafenib ${ }^{[6]}$. The molecular classification and predictive biomarkers may be necessary for further studies.

\section{WNT/B-catenin pathway}

WNT signaling pathway plays a role in organogenesis, regeneration and differentiation, and maintaining the homeostasis of tissues and organs. In liver tissue, hepatocytes, hepatic stellate cells and Kupffer cells could express this pathway ${ }^{[62]}$. There is growing evidence that WNT signaling pathway is involved in the development of HCC. The sequencing studies of HCC tissues have identified the frequently activating mutations of 
CTNNB1 or inactivating mutations of AXIN1 and APC, which caused the activation of the WNT/ $\beta$-catenin pathway. The activating mutations of CTNNB1 results in the mutated $\beta$-catenin accumulation and migration into the nucleus to activate transcription from target genes, which will promote HCC cell proliferation and stemness. HBV-related HCCs showed less frequent activating mutations of CTNNB1 and more frequent inactivation mutation of AXIN1 compared to HCCs related to HCV infection, alcohol consumption, or $\mathrm{NASH}$, which suggested that the mechanism of the WNT/ $\beta$-catenin signaling activation may be different in HCCs with different etiology ${ }^{[63]}$. A recent interesting study showed that deletion of endogenous $\beta$-catenin in hepatocytes of mice aggravated HCC development driven by an oncogenic version of $\beta$-catenin together with MET. This hepatocarcinogenesis featured up-regulation of Erk, Akt and WNT/ $\beta$-catenin signaling and cyclin D1 expression. The transcriptomics analysis of these mice tumors showed similar transcriptomes to human HCCs with concomitant CTNNB1 mutations and MET overexpression. The $\beta$-catenin-deficient livers displayed many changes including increased DNA damage response, expanded Sox9+ cells, and up-regulation of pro-tumorigenic cytokines like IL- 6 and TGF- $\beta 1$. This study together with previous studies suggested that both activating and inactivating mutations in CTNNB1, encoding $\beta$-catenin and activation of WNT- $\beta$-catenin pathway, play important roles in liver tumorigenesis in humans and mice ${ }^{[64]}$. Recent researches show that abnormal expression of wnt signaling pathway is involved in the intrahepatic inflammation, abnormal lipid metabolism and oxidative stress, with resulting in the occurrence of chronic liver diseases such as non-alcoholic fatty liver disease and liver fibrosis ${ }^{[65,66]}$.

\section{MAPK pathway}

Ras/Raf/MEK/MAPK is one of the key signal transduction pathways in the HCC. Many growth factors could activate residual tyrosine of Ras/Raf/MEK/MAPK to phosphorylate itself including EGF, IGF, VEGF, PDGF, FGFs and HGF. MAPK signal transduction is a three-step kinase cascade way, first of all MAPKKK is activated and phosphorylated by mitogen on the basis of the stimulation, the phosphorylated MAPKKK turns to activate MAP-KK, after which, the activated MAP-KK is able to phosphorylate MAPK and finally translocate into the nucleus. The main pathways of MAPK signaling pathway are Ras-Raf-ERK, c-Jun $\mathrm{N}$-terminal kinase (JNK), and p38- MAPK pathway ${ }^{[67]}$.

The Ras mutation on the oncogene activates Raf activation. The activated Raf activates it by phosphorylating the serine residues on the mitogen activated kinase kinase (MEK) loop, then MEK activates extracellular signalregulated kinases (ERKs). ERK can also be activated by decreasing the level of dual specificity phosphatase (DUSP), when the Ras mutation rate is low in HCC patients. Activated ERK in turn phosphorylates a number of substrates that are linked to the cytoplasm and membrane, while also rapidly translocated into the nucleus to dephosphorylate and activate transcriptional molecules involved in proliferative responses such as ELK-1, AP-1, TCF, and the others, which regulate the expression of ETS, c-Jun, c-Fos, c-Myc, and cyclin D in HCC and affect the prognosis of HCC ${ }^{[68]}$. In addition, activated ERK can regulate the phosphorylation of histone, the pro-apoptotic protein Bad and the transcription factor CREB by ribosomal S6 protein kinase-2 phosphorylation $^{[69]}$. Continuous activation of ERK results in the increase of phosphorylated ERK, which is the basis of hepatoma cell proliferation and invasion ${ }^{[70]}$.

JNK pathway maintains cell cycle continuity mainly through activation of JNK activating transcription factor c-Jun synergistic with ERK pathway ${ }^{[69]}$. Activated JNK is not only bound to transcription factors ATF2 and c-Jun amino-terminal domain, phosphorylation of the active region of the transcription factor, activation of the transcription factor AP-1, up-regulating the expression of apoptotic precursors CD95 and TNF- $\alpha^{[7]}$, but also regulates phosphorylation of Bcl-2 indirectly after being activated, through the mitochondrial pathway to diminish its anti-apoptotic ability. Studies have shown that JNK pathway can affect the invasion and metastasis of HCC cell line MHCC97H, and that JNK inhibitor can affect human HCC xenografts and increase chemically inducing murine liver cancer ${ }^{[72,73]}$. 


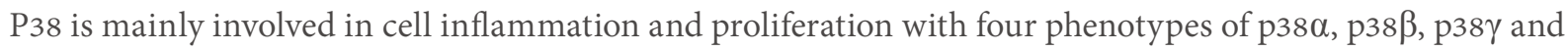
p38 8 . P38 $\alpha$. The most important factor in the p38 MAPK pathway, regulates the release of inflammatory cytokines such as IL-1 $\beta$, IL- 6 and TNF- $\alpha$, and also increases ROS activity inducing hepatocyte apoptosis ${ }^{[74]}$. The p38 pathway can down-regulate the expression of cyclin D1 and block the cell cycle in G1-S and G2-M, and can also affect the downstream gene GADD45A of the ringing tumor suppressor gene p53 to regulate the development of early $\mathrm{HCC}^{[75]}$. An interesting mouse study suggested that inhibiting p38 MAPK (MAPK14) could help treat the sorafenib resistant liver cancers. In a mouse model of sorafenib-resistant HCC, it was discovered through in vivo screening of a shRNA library that p38 MAPK knockdown contributed sensitivity to sorafenib. In other mouse models of HCC, sorafenib and a p38 MAPK shRNA or a small molecule MAPK14 inhibitor skepinone-L increased survival of mice with HCC compared with sorafenib alone ${ }^{[76]}$.

\section{NF- $\kappa B$ pathway}

$\mathrm{NF}-\kappa \mathrm{B}$ activation induces several pro-inflammatory cytokines which are prominent in supporting the progression of cancer ${ }^{[77,78]}$. Chronic infection and inflammatory response are closely related to tumorigenesis. $\mathrm{HCC}$ is the result of chronic inflammatory response induced by hepatitis $\mathrm{B} / \mathrm{C}^{[79]}$. IKK/NF- $\kappa \mathrm{B}$ pathway plays an important role in hepatitis, liver fibrosis and HCC. NF- $\mathrm{BB}$ is a class of nucleoprotein factors with

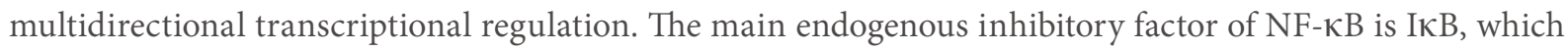
makes NF- $\kappa B$ remain in the cytoplasm and inhibits its nuclear translocation. NF- $\kappa B$ is phosphorylated by

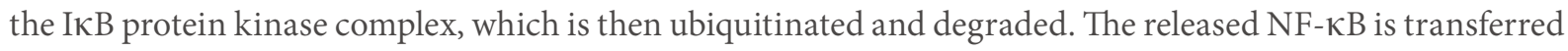
from the cytoplasm to the nucleus, and then regulates Inhibition of apoptosis proteins (IAPs), Bcl-2 family, TNFR-associated factor (TRAF-1, TRAF-2) and JNK in the cell ${ }^{[80-82]}$.

Continued abnormal activation of NF- $\mathrm{KB}$ in hepatocytes results in the development of cholestatic hepatitis and HCC. Inhibition of NF- $\kappa \mathrm{B}$ can affect the normal apoptosis of hepatocytes ${ }^{[82]}$. Blocking IKK/NF- $\mathrm{B}$ signal transduction pathway may reduce hepatic inflammation from chronic inflammation ${ }^{[80]}$. It is possible to prevent the development of HCC by blocking the abnormal JNK pathway activation and scavenging ROS products and other ways to maintain the normal physiological level of NF- $\kappa B$ in the liver ${ }^{[83,84]}$. However, $\mathrm{NF}-\kappa \mathrm{B}$ is often of over-abundant activation in liver cells to facilitate HCC transformation. Therefore, how to remove overactive NF- $\mathrm{\kappa B}$ and maintain it at normal physiological levels is the key to prevention and treatment of HCC.

\section{VEGF pathway}

VEGF is a multifunctional cytokine that promotes endothelial cell division, proliferation and angiogenesis, monocyte migration, and induction of inflammatory cytokines ${ }^{[85,86]}$. Liver VEGF is mainly present in hepatocytes and endothelial cells with the VEGF receptors. Chronic liver disease includes hepatocyte atypical hyperplasia, adenoid hyperplasia, nodules and other regenerative processes. The expression of VEGF in cancer tissue initiates the neovascularization. In the early stage of liver disease, VEGF overexpression can cause the increase of blood VEGF. VEGF levels in HCC patients are higher than in patients with chronic hepatitis and cirrhosis. The increase of VEGF is negatively correlated with the prognosis of liver cancer ${ }^{[8788]}$. The current only FDA approved first line therapeutic drug for advanced HCC, sorafenib, is also a tyrosine kinase inhibitor (TKI) directed against the VEGF family. The ALICE-1 study suggested that the analysis of VEGF and VEGFR SNPs may represent a potential clinical tool for better selection of HCC patients who are more likely to benefit from sorafenib treatment. Currently, apatinib (YN968D1), a TKI that selectively inhibits the VEGFR2, is actively studied in advanced HCC alone or combination with TACE (NCT03046979, NCT03398122).

JAK/STAT pathway

In 1994, Darnell et al. ${ }^{[89]}$ found JAK-STAT pathway. It was a new extremely fast signaling pathway, which can transmit extracellular signals to the nucleus and through tyrosine kinase signaling and transcription 
activator targets. The activation eventually leads to biological effects. JAKs family belongs to the nonreceptor tyrosine kinase, so far there are 4 members of family: JAK1, JAK2, JAK3 and TYK2, with diverse sizes, molecular weight between $120-140 \mathrm{kDa}$ and evolution degree conservative ${ }^{[00]}$. STATs are a kind of cytoplasmic proteins, associating with target genes binding. STATs are downstream substrates for JAKs. After abnormal activation of JAK/STAT3 signaling pathway, p-STAT3 can bind to specific DNA in the nucleus and directly or indirectly up-regulate the expression of apoptotic genes and thus regulate cell proliferation and apoptosis ${ }^{[91]}$. STAT is highly expressed in many human malignant tumor tissues and cell lines, especially STAT3, which is currently considered as an oncogene and may promote the occurrence and development of liver cancer by influencing cell growth, differentiation and apoptosis ${ }^{[92,93]}$. Many evidence suggest possible interactions between STAT3 and NF- $\mathrm{KB}$ signaling pathways. STAT3 can promote p65 into the nucleus, resulting in NF- $\mathrm{KB}$ activation. JAK/STAT signaling pathway also play a part in pancreatic elastase-induced secretion of interleukin-18 ${ }^{[94]}$. Injection of JAK2 inhibitor AG490 significantly inhibited the activation of JAK2-STAT3 after hepatic ischemia, and decreased the activation of NF- $\kappa B$ and TNF ${ }^{[95]}$. A phase I/Ib study has been completed to assess the safety and anti-tumour activity of AZD9150 in patients with advanced/ metastatic HCC (NCT01839604).

\section{EGFR signaling pathway}

The EGFR is a tyrosine kinase that contributes to the regulation of cellular homeostasis. It is a $170-\mathrm{KDa}$ membrane protein that stimulates downstream cell proliferation, survival, and tumorigenesis ${ }^{[96]}$. Members of the human ErbB/HER receptor family include EGFR (ErbB1/HER1), ErbB2 (HER2/neu), ErbB3 (HER3) and ErbB4 (HER4). EGFR encoded by the proto-oncogene erbB1 with EGFR ligand family members of 10 , such as EGF, transforming growth factor- $\alpha$ (TGF- $\alpha$ ), amphiregulin, b cytokines, heparin-binding EGF and epidermal regulatory elements ${ }^{[97]}$. EGFR activation can activate extracellular downstream signaling transduction pathways such as ERKs-MAPK and PI3K. It is involved in the regulation of cell division, differentiation and proliferation and promotes the repair of tissue injury. It is also closely related to tumor cell cycle progression, apoptosis inhibition, tumor angiogenesis and cell motility and invasion ${ }^{[98,99]}$. EGFR is highly expressed in hepatoma cells stimulated by TGF- $\alpha$ or EGF. In vitro and in vivo experiments show that EGFR blockade can inhibit HCC proliferation and metastasis through the EGFR pathway, and have synergistic effect of HGF treatment with other growth factor signaling pathways ${ }^{[100]}$. Currently, a pilot clinical trial studies the best dose of EGFR inhibitor erlotinib hydrochloride for preventing liver cancer in patients with scarring (cirrhosis) of the liver undergoing surgery. Erlotinib hydrochloride may help to prevent the development of fibrosis/cirrhosis and liver cancer in patients liver cirrhosis (NCT02273362).

\section{TLR signaling pathway}

TLR is a transmembrane protein present on the surface of human cells. TLR plays an important role in the innate immune response in the body as a major pattern recognition receptor. Currently, more than a dozen TLR have been found in the human body and they are widely distributed in various tissues with the specificity of cells and tissue distribution. TLR4, a natural receptor for LPS, plays an important role in the regulation of acute inflammatory responses, transduction of cell signals and apoptosis ${ }^{[101]}$. During liver fibrosis in rats, the expression of TLR4 protein in liver showed that compared with the normal control group, the level of hydroxyproline in liver tissue began to increase significantly ${ }^{[102]}$, and the level of plasma endotoxin in model group increased gradually with a significant positive correlation between the content of hydroxyproline after $\mathrm{CCl} 4$ treatment ${ }^{[103]}$. In $\mathrm{HCV}$ patients, the severity of the disease is associated with the expression of TLR2/4 mRNA ${ }^{[104]}$. Compared with the normal group, TLR2/4 mRNA expression of chronic hepatitis $\mathrm{C}$ patients were elevated. The study found that TLR4-MyD88-NF- $\kappa \mathrm{B}$ signaling pathway plays an important regulatory role in abnormal liver immune response, inflammatory response-triggered liver injury, activation of hepatic stellate cells and the progression of hepatic fibrosis ${ }^{[05]}$. 


\section{INHIBITORS OF INFLAMMATION FOR THE PREVENTION AND TREATMENT OF LIVER CANCER}

As mentioned above, a large number of in vitro and in vivo experiments and some clinical studies have confirmed that chronic inflammation plays a key role in the development of HCC. Understanding the cytokines and signaling pathways required for the transmission of inflammation in HCC is more conducive to understanding the occurrence of HCC development, and can also provide some reference value for drug research and development. The following will discuss in detail some anti-inflammation agents in the potential of liver cancer treatment, which mainly was divided into two categories, natural medicine and synthetic drugs.

\section{Natural anti-inflammatory agents}

Natural medicine refers to modern medicine system that has a certain pharmacological activity of animal medicine, botanical medicine, mineral medicine, fruits, vegetables or spices. A large number of studies show that many natural anti-inflammatory drugs also have both cancer prevention and treatment potential. Many articles reported that natural products could be potentially used for the prevention and treatment of liver cancer through diet.

Curcumin, a chemical derived from the rhizomes of some plants from the family Zingiberaceae, is a diketone. Curcumin has a variety of pharmacological activities, including lipid-lowering, anti-tumor, antiinflammatory, gallbladder, anti-oxidation and other effects ${ }^{[106]}$. Existing research shows that curcumin can inhibit DEN-induced NF- $\kappa \mathrm{B}$ expression in liver tissue. Curcumin can also inhibit DEN-induced HCC by inhibiting the expression of IL-2 and IL-6 and promoting Gpx, GRE and SOD activities ${ }^{[107]}$. El-Houseini et al. ${ }^{[108]}$ found that curcumin and taurine combination may be a new way to prevent liver cancer.

In 1940, resveratrol was first isolated from the roots of the leaf-walnut. In recent years, many studies have shown that resveratrol has anti-cancer, anti-cardiovascular disease, weight loss, anti-bacterial, antiinflammatory, anti-oxidation pharmacological properties ${ }^{[109]}$. In vitro experiments showed that the migration and invasion of HepG2 cells are inhibited by resveratrol, which decrease the expression of MMP-2, MMP-9 and NF- $\kappa B$ nuclear transfer ${ }^{[110,111]}$. Resveratrol was also been shown to inhibit SIRT1 mediated PI3K/AKT pathway, thereby down-regulating Bcl-2, caspase-3 and caspase-7 expression ${ }^{[12]}$. DMU-212, a resveratrol analogue, has been reported to have effect on antioxidant status and apoptosis-related genes in rat model of hepatocarcinogenesis ${ }^{[113]}$.

$\mathrm{N}$-acetylcysteine (NAC), a water soluble organosulfur compound present in garlic, is a classic anti-oxidant. Studies have shown that abnormal oxidative stress occurs in hepatocarcinoma. When NAC is used in hepatic stellate cells (HSCs), it can inhibit hepatic fibrosis and HCC development ${ }^{[14]}$. Moreover, the use of NAC in HCC mice inhibited the high expression of GST, which may be related to insulin-like growth factor I (IGF-I) and iNOS $^{[115,116]}$.

Gallic acid (GA) is an organic acid, which is the main component of many herbs such as dogwood and rhubarb. Experimental studies have shown that GA can inhibit the proliferation of HepG2 cells by inhibiting the expression of IL-8 and promoting the expression of IL-10 and IL-12 ${ }^{[117]}$. In the SMMC-7721 cells, GA induced caspase-3, caspase-9 and reactive oxygen species (ROS) activity ${ }^{[118]}$. N-nitrosodiethylamine induces the high serum levels of alpha-fetoprotein, glypican-3, and STAT3. Those can all be inhibited by GA through activation of p38 in HepG2 to produce anti-oxidant effect ${ }^{[119]}$.

Flavonoids are a class of secondary metabolites of plants derived from a wide range of sources and can be derived from fruits, vegetables, roots, stems, flowers, beans, and daily intake of beverages such as tea and wine. Among them, baicalein, quercetin and genistein are three simpler and more studied agents. Baicalein is derived from plant scutellaria baicalensis. Studies have reported that baicalein can inhibit the proliferation 
of Bel-7402 cells through periodic blockade ${ }^{[120]}$. The process involves mainly involved in MAPK, Wnt, Hippo and PI3K-Akt/mTOR signaling pathways ${ }^{[121]}$. Quercetin can enhance the antiproliferative effect of IFN- $\alpha$ in hepatocarcinoma cells by inhibiting SHP2 phosphatase activation of JAK/STAT signaling pathway ${ }^{[122]}$. The results showed that quercetin nanoparticles could inhibit caspase/Cyto-c signaling pathway, inhibit AP-2 and NF- $\kappa B$, block Akt/ERK signaling pathway to play an antitumor effect ${ }^{[123]}$. Genistein can induce HCC cell death by regulating the inhibition of aerobic glycolysis by HIF-1 $\alpha$, and genistein can regulate gene products Cyclin D1, Bcl-xL, Bcl-2, c-myc and COX-2 by inhibiting NF- $\kappa B$ and VEGF expression, and then alleviate the occurrence and development of HCC ${ }^{[124]}$.

Myrtenal is an important variety of spices, has been widely used in daily chemical, pharmaceutical, food and other industries. Studies have shown that, as a natural monoterpene, Myrtenal can inhibit DEN-induced high expression of TNF- $\alpha$ in $\mathrm{HCC}^{[125]}$. Myrtenal also improves DEN-induced hepatocarcinogenesis by activating tumor suppressor protein 553 and modulating lysosomal and mitochondrial enzymes ${ }^{[125]}$.

Hesperidin is a chalcone compound. Many articles have reported that it has a good anti-liver cancer effect was shown through the Wnt pathway, ROS, ATP and calcium ${ }^{[126-128]}$. More importantly, hesperidin on tumor cell invasion inhibition was realized mainly through inhibition of AP-1 and NF- $\kappa$ B in human HCC cells ${ }^{[129]}$.

\section{Synthetic anti-inflammatory agents}

Aspirin is a clinical analgesic and antipyretic drug. Due to its long clinical application and high safety, research on its multiple clinical conditions is now receiving great attention. At present, studies have shown that aspirin has good anti-tumor activity ${ }^{[130]}$. Among them, the application of liver cancer has been gradually reflected. A large number of clinical studies have shown that long-term use of aspirin in HCC patients can inhibit the expression of AMPK, mTOR and $\beta$-catenin and thus inhibit the progress of liver cancer ${ }^{[131]}$. Our recent study suggested aspirin as a promising chemopreventive and chemotherapeutic agent for liver cancer. There is a current prospective randomized controlled trial registered in China to investigate the effect of sorafenib combined with aspirin in preventing patient risk for postoperative surgical recurrence of HCC (NCT02748304). We have demonstrated that by combining low-dose sorafenib and aspirin, the synergistic antitumor effects observed are related to the simultaneously silencing of ACSL4 and the induction of GADD45B expression. The clinical survival of HCC patients expressing ACSL $4{ }^{\text {high }}$ GADD $45^{\text {low }}$ was significantly poorer compared to patients with ACSL $4{ }^{\text {low }} \mathrm{GADD} 45 \mathrm{~B}^{\text {high }}$ expression, thus demonstrating the potential clinical value of combining aspirin and sorafenib to treat HCC patients expressing $\operatorname{ACSL} 4^{\text {high }} G A D D 45^{\text {low }[132]}$.

There are so many special COX2-inhibitors, like celecoxib, etodolac, JTE-522 and nimesulide. Even though those are COX-2 inhibitors, their principles of pharmacological activity are different. Celecoxib inhibited the translocation of p65 to the nucleus from the cytoplasm ${ }^{[133]}$. R-Etodolac (at physiological doses) and Celecoxib (at high concentrations) on HCC cells were accompanied by the down-regulation of $\beta$-catenin ${ }^{[134]}$. CDAA model activated hepatic stellate cells and promoted CD45-positive inflammatory cells coming in the liver. JTE-522 can attenuate all the change ${ }^{[135]}$. Nimesulide inhibits the proliferation of HepG2 by up-regulation of Smad4 and downregulation of HSP70 gene expression of SMMC-7721 ${ }^{[136]}$. Roxithromycin is a new generation of macrolide antibiotics. It inhibits constitutive activation of NF- $\mathrm{B}$ by diminishing oxidative stress or suppressing VEGF production in a rat model of $\mathrm{HCC}^{[137]}$. Erlotinib, a special EGFR inhibitor, involves in development of HCC. It is reported that EGFR-ERK pathway has been inhibited by erlotinib in HCC model ${ }^{[138]}$. However, due to extensive use of erlotinib, some patients with HCC in clinical trials have become resistant. Therefore, the study turned to combination therapy ${ }^{[139-141]}$. In the literature, neurotensin regulation induces overexpression and activation of EGFR in HCC and restores response to erlotinib ${ }^{[142]}$. 


\section{CONCLUSION}

Inflammation is one of the key factors to promote liver malignant transformation. A better understanding of the molecular processes of inflammation-cancer transformation in the development of primary liver cancer will be important to developing early detection for HCC and new drugs to efficiently prevent de novo hepatocarcinogenesis. It has been shown that inflammatory microenvironment constitutes different immune cells. Currently, overcoming antitumor immunity by immune checkpoint inhibitors represents one of the most promising therapeutic strategies for the treatment of many cancers including HCC $^{[143]}$. Some immune checkpoint inhibitors, such as anti-programmed death 1/programmed death-ligand 1 antibodies, have recently been reported in the promising clinical trial results. The Food and Drug Administration in United State has approved the nivolumab to be used for advanced HCC patients who fail to respond to firstline treatment ${ }^{[144]}$. There are still no effective chemoprevention strategies in patients at high risk for HCC development besides the viral eradication in patients with viral hepatitis ${ }^{[143]}$. We proposed that aspirin, a nonsteroidal anti-inflammatory drug, may emerge as a promising chemopreventive and chemotherapeutic agent for $\mathrm{HCC}^{[132]}$. There are great opportunities to further understand inflammation-cancer transformation and developing pharmacological strategies for preventing inflammation and HCC development and recurrence.

\section{DECLARATIONS}

\section{Authors' contributions}

Drafted the outline of this review: Chen HJ, Xia HP

Drafted the manuscript: Chen HJ, Hu MH, Xu FG, Xu HJ, Xia HP

Finalized the manuscript: She JJ, Xia HP

\section{Availability of data and materials}

Not applicable.

\section{Financial support and sponsorship}

This work was supported by grants from National Young 1000 Talents Program of China, Jiangsu Province Education Department Grant, Southeast University-Nanjing Medical University Cooperative Research Project, Young Talent Support Plan of Xi'an Jiaotong University and Hundred Talents Program of Shaanxi.

\section{Conflicts of interest}

All authors declared that there are no conflicts of interest.

\section{Ethical approval and consent to participate}

Not applicable.

\section{Consent for publication}

Not applicable.

\section{Copyright}

(c) The Author(s) 2018.

\section{REFERENCES}

1. Sia D, Villanueva A, Friedman SL, Llovet JM. Liver cancer cell of origin, molecular class, and effects on patient prognosis. Gastroenterology 2017;152:745-61.

2. Sherman M. Hepatocellular carcinoma: epidemiology, risk factors, and screening. Semin Liver Dis 2005;25:143-54.

3. Nguyen VT, Law MG, Dore GJ. An enormous hepatitis B virus-related liver disease burden projected in Vietnam by 2025 . Liver Int 2008;28:525-31.

4. El-Serag HB, Rudolph KL. Hepatocellular carcinoma: epidemiology and molecular carcinogenesis. Gastroenterology 2007;132:2557-76. 
5. Ikeda M, Morizane C, Ueno M, Okusaka T, Ishii H, Furuse J. Chemotherapy for hepatocellular carcinoma: current status and future perspectives. Jpn J Clin Oncol 2018;48:103-14.

6. Stroffolini T, Sagnelli E, Andriulli A, Colloredo G, Furlan C, Gaeta G, Morisco F, Pirisi M, Rosina F, Sagnelli C, Smedile A, Almasio P. Sex difference in the interaction of alcohol intake, hepatitis B virus, and hepatitis C virus on the risk of cirrhosis. PLoS One 2017; 12:e0185710.

7. Nakagawa H, Maeda S, Yoshida H, Tateishi R, Masuzaki R, Ohki T, Hayakawa Y, Kinoshita H, Yamakado M, Kato N, Shiina S, Omata M. Serum IL-6 levels and the risk for hepatocarcinogenesis in chronic hepatitis $\mathrm{C}$ patients: an analysis based on gender differences. Int $\mathrm{J}$ Cancer 2009; 125:2264-9.

8. von Mehren M, Rankin C, Goldblum J, Demetri G, Bramwell V, Ryan C, Borden E. Phase 2 Southwest Oncology Group-directed intergroup trial (S0505) of sorafenib in advanced soft tissue sarcomas. Cancer 2012;118:770-6.

9. Coussens LM, Werb Z. Inflammation and cancer. Nature 2002;420:860-7.

10. Nakagawa H, Maeda S. Inflammation- and stress-related signaling pathways in hepatocarcinogenesis. World J Gastroenterol 2012;18:4071-81.

11. Inoue J, Ninomiya M, Shimosegawa $\mathrm{T}$, McNiven M. Cellular membrane trafficking machineries utilized by the hepatitis viruses. Hepatology 2018; doi: 10.1002/hep.29785.

12. Leung N. HBV and liver cancer. Med J Malaysia 2005;60 Suppl B:63-6.

13. Lu J, Chuang L, Yang W, Tai T, Lai M, Chen P, Kao J, Lee C, Lee H. Adiponectin levels among patients with chronic hepatitis B and C infections and in response to IFN-alpha therapy. Liver Int 2005;25:752-9.

14. Di Fazio I, Motta M, Musumeci S, Neri S, Pistone G, Malaguarnera M. Efficacy of human recombinant erythropoietin plus IFN-alpha in patients affected by chronic hepatitis C. J Interferon Cytokine Res 2004;24:594-9.

15. Nan J, Xing Y, Hu B, Tang J, Dong H, He Y, Ruan D, Ye Q, Cai J, Ma X, Chen J, Cai X, Lin Z, Wu X, Li X. Endoplasmic reticulum stress induced LOX-1+ CD15+ polymorphonuclear myeloid-derived suppressor cells in hepatocellular carcinoma. Immunology 2018; $154: 144-55$.

16. Liu M, Jin L, Sun S, Liu P, Feng X, Cheng Z, Liu W, Guan K, Shi Y, Yuan H, Xiong Y. Metabolic reprogramming by PCK1 promotes TCA cataplerosis, oxidative stress and apoptosis in liver cancer cells and suppresses hepatocellular carcinoma. Oncogene 2018;37:1637-53.

17. Rabachini T, Fernandez-Marrero Y, Montani M, Loforese G, Sladky V, He Z, Bachmann D, Wicki S, Villunger A, Stroka D, Kaufmann T. BOK promotes chemical-induced hepatocarcinogenesis in mice. Cell Death Differ 2018;25:706-18.

18. Wang B, Fu J, Yu T, Xu A, Qin W, Yang Z, Chen Y, Wang H. Contradictory effects of mitochondria- and non-mitochondria-targeted antioxidants on hepatocarcinogenesis by altering DNA repair in mice. Hepatology 2017; doi: 10.1002/hep.29518.

19. Aggarwal BB, Shishodia S, Sandur SK, Pandey MK, Sethi G. Inflammation and cancer: how hot is the link? Biochem Pharmacol 2006; $72: 1605-21$.

20. Guo Y, Zhao Q, Cao L, Zhao B. Hepatoprotective effect of Gan Kang Yuan against chronic liver injury induced by alcohol. J Ethnopharmacol 2017;208:1-7.

21. Hamilton DL, Vest TK, Brown BS, Shah AN, Menguy RB, Chey WY. Liver injury with alcoholiclike hyalin after gastroplasty for morbid obesity. Gastroenterology 1983;85:722-6.

22. Kaplan JM, Nowell M, Lahni P, Shen H, Shanmukhappa SK, Zingarelli B. Obesity enhances sepsis-induced liver inflammation and injury in mice. Obesity (Silver Spring) 2016;24:1480-8.

23. Kirpich I, McClain C. More alcohol, more liver injury: not always true. Alcohol Alcohol 2017;52:627-8.

24. Marin V, Poulsen K, Odena G, McMullen MR, Altamirano J, Sancho-Bru P, Tiribelli C, Caballeria J, Rosso N, Bataller R, Nagy LE. Hepatocyte-derived macrophage migration inhibitory factor mediates alcohol-induced liver injury in mice and patients. J Hepatol 2017;67:1018-25.

25. Williams JA, Manley S, Ding WX. New advances in molecular mechanisms and emerging therapeutic targets in alcoholic liver diseases. World J Gastroenterol 2014;20:12908-33.

26. Liu Z, Ning F, Wang H, Chen D, Cai Y, Sheng H, Lash G, Liu L, Du J. Epidermal growth factor and tumor necrosis factor $\alpha$ cooperatively promote the motility of hepatocellular carcinoma cell lines via synergistic induction of fibronectin by NF- $\mathrm{\kappa B} / \mathrm{p} 65$. Biochim Biophys Acta 2017;1861:2568-82.

27. Huang B, Lin C, Wang C, Kao S. Upregulation of heat shock protein 70 and the differential protein expression induced by tumor necrosis factor-alpha enhances migration and inhibits apoptosis of hepatocellular carcinoma cell HepG2. Int J Med Sci 2017;14:284-93.

28. Zhang Q, Wang H, Mao C, Sun M, Dominah G, Chen L, Zhuang Z. Fatty acid oxidation contributes to IL-1 $\beta$ secretion in M2 macrophages and promotes macrophage-mediated tumor cell migration. Mol Immunol 2017;94:27-35.

29. Zhang J, Zhang Q, Lou Y, Fu Q, Chen Q, Wei T, Yang J, Tang J, Wang J, Chen Y, Zhang X, Zhang J, Bai X, Liang T. Hypoxiainducible factor-1 $\alpha /$ interleukin- $1 \beta$ signaling enhances hepatoma epithelial-mesenchymal transition through macrophages in a hypoxicinflammatory microenvironment. Hepatology 2018;67:1872-89.

30. Wadkin J, Patten D, Kamarajah S, Shepherd E, Novitskaya V, Berditchevski F, Adams D, Weston C, Shetty S. CD151 supports VCAM1-mediated lymphocyte adhesion to liver endothelium and is upregulated in chronic liver disease and hepatocellular carcinoma. Am J Physiol Gastrointest Liver Physiol 2017;313:G138-49.

31. Castelli G, Pelosi E, Testa U. Liver cancer: molecular characterization, clonal evolution and cancer stem cells. Cancers (Basel) 2017;9:E127.

32. Guo W, Liu S, Cheng Y, Lu L, Shi J, Xu G, Li N, Cheng K, Wu M, Cheng S, Liu S. ICAM-1-related noncoding RNA in cancer stem cells maintains ICAM-1 expression in hepatocellular carcinoma. Clin Cancer Res 2016;22:2041-50. 
33. Bayo J, Real A, Fiore E, Malvicini M, Sganga L, Bolontrade M, Andriani O, Bizama C, Fresno C, Podhajcer O, Fernandez E, Gidekel M, Mazzolini G, García M. IL-8, GRO and MCP-1 produced by hepatocellular carcinoma microenvironment determine the migratory capacity of human bone marrow-derived mesenchymal stromal cells without affecting tumor aggressiveness. Oncotarget 2017;8:80235-48.

34. Shao Y, Lin H, Li Y, Lee Y, Chen H, Cheng A, Hsu C. High plasma interleukin-6 levels associated with poor prognosis of patients with advanced hepatocellular carcinoma. Jpn J Clin Oncol 2017;47:949-53.

35. Hayashi T, Yamashita T, Terashima T, Suda T, Okada H, Asahina Y, Hayashi T, Hara Y, Nio K, Sunagozaka H, Takatori H, Arai K, Sakai Y, Yamashita T, Mizukoshi E, Honda M, Kaneko S. Serum cytokine profiles predict survival benefits in patients with advanced hepatocellular carcinoma treated with sorafenib: a retrospective cohort study. BMC Cancer 2017;17:870.

36. Ding Y, Wu Z, Wei Y, Shu L, Peng Y. Hepatic inflammation-fibrosis-cancer axis in the rat hepatocellular carcinoma induced by diethylnitrosamine. J Cancer Res Clin Oncol 2017;143:821-34.

37. Yan B, Wang H, Rabbani ZN, Zhao Y, Li W, Yuan Y, Li F, Dewhirst MW, Li CY. Tumor necrosis factor-alpha is a potent endogenous mutagen that promotes cellular transformation. Cancer Res 2006;66:11565-70.

38. Lu H, Han M, Yuan X, Tursun K, Zhang Y, Li Y, Li Z, Feng S, Zhou L, Pan Z, Wang Q, Han K, Liu S, Cheng J. Role of IL-6-mediated expression of NS5ATP9 in autophagy of liver cancer cells. J Cell Physiol 2017; doi: 10.1002/jcp.26343.

39. Wu X, Dong L, Lin X, Li J. Relevance of the NLRP3 inflammasome in the pathogenesis of chronic liver disease. Front Immunol 2017;8:1728.

40. Karin M. The IkappaB kinase - a bridge between inflammation and cancer. Cell Res 2008;18:334-42.

41. Trasino S, Tang X, Jessurun J, Gudas L. A retinoic acid receptor $\beta 2$ agonist reduces hepatic stellate cell activation in nonalcoholic fatty liver disease. J Mol Med 2016;94:1143-51.

42. Harvey W, Jurgensen K, Pu X, Lamb C, Cornell K, Clark R, Klocke C, Mitchell K. Exposure to 2,3,7,8-tetrachlorodibenzo-p-dioxin (TCDD) increases human hepatic stellate cell activation. Toxicology 2016;344-346:26-33.

43. Vanegas N, Vernot J. Loss of quiescence and self-renewal capacity of hematopoietic stem cell in an in vitro leukemic niche. Exp Hematol Oncol 2017;6:2.

44. Han K, Han H, He X, Wang L, Guo X, Zhang X, Chen J, Zhu Q, Nian H, Zhai X, Jiang M. Chemokine CXCL1 may serve as a potential molecular target for hepatocellular carcinoma. Cancer Med 2016;5:2861-71.

45. Cortes M, Chen M, Stachura D, Liu S, Kwan W, Wright F, Vo L, Theodore L, Esain V, Frost I, Schlaeger T, Goessling W, Daley G, North T. Developmental vitamin D availability impacts hematopoietic stem cell production. Cell Rep 2016;17:458-68.

46. Jeng K, Jeng C, Jeng W, Chang C, Sheen I. Role of C-X-C chemokine ligand 12/C-X-C chemokine receptor 4 in the progression of hepatocellular carcinoma. Oncol Lett 2017;14:1905-10.

47. Kisen GO, Tessitore L, Costelli P, Gordon PB, Schwarze PE, Baccino FM, Seglen PO. Reduced autophagic activity in primary rat hepatocellular carcinoma and ascites hepatoma cells. Carcinogenesis 1993;14:2501-5.

48. Silvente-Poirot S, Ségala G, Poirot M, Poirot M. Ligand-dependent transcriptional induction of lethal autophagy: a new perspective for cancer treatment. Autophagy 2018;14:555-7.

49. Mi Y, Xiao C, Du Q, Wu W, Qi G, Liu X. Momordin Ic couples apoptosis with autophagy in human hepatoblastoma cancer cells by reactive oxygen species (ROS)-mediated PI3K/Akt and MAPK signaling pathways. Free Radic Biol Med 2016;90:230-42.

50. Sun H, Zou S, Candiotti K, Peng Y, Zhang Q, Xiao W, Wen Y, Wu J, Yang J. Octreotide attenuates acute kidney injury after hepatic ischemia and reperfusion by enhancing autophagy. Sci Rep 2017;7:42701.

51. Zeng Y, Lian S, Li D, Lin X, Chen B, Wei H, Yang T. Anti-hepatocarcinoma effect of cordycepin against NDEA-induced hepatocellular carcinomas via the PI3K/Akt/mTOR and Nrf2/HO-1/NF- $\mathrm{KB}$ pathway in mice. Biomed Pharmacother 2017;95:1868-75.

52. Vangan N, Cao Y, Jia X, Bao W, Wang Y, He Q, Binderiya U, Feng X, Li T, Hao H, Wang Z. mTORC1 mediates peptidoglycan induced inflammatory cytokines expression and NF- $\mathrm{kB}$ activation in macrophages. Microb Pathog 2016;99:111-8.

53. Sui W, Zhang Y, Wang Z, Wang Z, Jia Q, Wu L, Zhang W. Antitumor effect of a selective COX-2 inhibitor, celecoxib, may be attributed to angiogenesis inhibition through modulating the PTEN/PI3K/Akt/HIF-1 pathway in an $\mathrm{H}_{22}$ murine hepatocarcinoma model. Oncol Rep 2014;31:2252-60.

54. Zhu Y, Zheng B, Wang H, Chen L. New knowledge of the mechanisms of sorafenib resistance in liver cancer. Acta Pharmacol Sin 2017;38:614-22.

55. Yang H, Wang J, Fan J, Zhang Y, Zhao J, Dai X, Liu Q, Shen Y, Liu C, Sun W, Sun Y. Ilexgenin A exerts anti-inflammation and antiangiogenesis effects through inhibition of STAT3 and PI3K pathways and exhibits synergistic effects with Sorafenib on hepatoma growth. Toxicol Appl Pharmacol 2017;315:90-101.

56. Johnson C, Tee A. Exploiting cancer vulnerabilities: mTOR, autophagy, and homeostatic imbalance. Essays Biochem 2017;61:699-710.

57. Chen H, Huang Y, Huang J, Lin L, Wei G. Gigantol attenuates the proliferation of human liver cancer HepG2 cells through the PI3K/ Akt/NF-kB signaling pathway. Oncol Rep 2017;37:865-70.

58. Zhao L, Li C, Liu F, Zhao Y, Liu J, Hua Y, Liu J, Huang J, Ge C. A blockade of PD-L1 produced antitumor and antimetastatic effects in an orthotopic mouse pancreatic cancer model via the PI3K/Akt/mTOR signaling pathway. Onco Targets Ther 2017;10:2115-26.

59. Wu L, Wang G, Liu S, Wei J, Zhang S, Li M, Zhou G, Wang L. Synthesis and biological evaluation of matrine derivatives containing benzo- $\alpha$-pyrone structure as potent anti-lung cancer agents. Sci Rep 2016;6:35918.

60. Huang Z, Su G, Hu W, Bi X, Zhang L, Wan G. The study on expression of CIAPIN1 interfering hepatocellular carcinoma cell proliferation and its mechanisms. Eur Rev Med Pharmacol Sci 2017;21:3054-60.

61. Zhu AX, Kudo M, Assenat E, Cattan S, Kang YK, Lim HY, Poon RT, Blanc JF, Vogel A, Chen CL. Effect of everolimus on survival in advanced hepatocellular carcinoma after failure of sorafenib: the EVOLVE-1 randomized clinical trial. JAMA 2014;312:57-67. 
62. Chen J, Rajasekaran M, Xia H, Zhang X, Kong S, Sekar K, Seshachalam V, Deivasigamani A, Goh B, Ooi L, Hong W, Hui K. The microtubule-associated protein PRC1 promotes early recurrence of hepatocellular carcinoma in association with the Wnt/ $\beta$-catenin signalling pathway. Gut 2016;65:1522-34.

63. Levrero M, Zucman-Rossi J. Mechanisms of HBV-induced hepatocellular carcinoma. J Hepatol 2016;64:S84-101.

64. Liang Y, Feng Y, Zong M, Wei X, Lee J, Feng Y, Li H, Yang G, Wu ZJ, Fu XD. $\beta$-catenin deficiency in hepatocytes aggravates hepatocarcinogenesis driven by oncogenic $\beta$-catenin and MET. Hepatology 2018;67:1807-22.

65. Yin Y, Li F, Li S, Cai J, Shi J, Jiang Y. TLR4 Influences hepatitis B virus related hepatocellular carcinoma by regulating the Wnt/ $\beta$-catenin pathway. Cell Physiol Biochem 2017;42:469-79.

66. Wang S, Song K, Srivastava R, Dong C, Go G, Li N, Iwakiri Y, Mani A. Nonalcoholic fatty liver disease induced by noncanonical Wnt and its rescue by Wnt3a. FASEB J 2015;29:3436-45.

67. Kyriakis J, Avruch J. Mammalian MAPK signal transduction pathways activated by stress and inflammation: a 10-year update. Physiol Rev 2012;92:689-737.

68. Pu W, Li J, Zheng Y, Shen X, Fan X, Zhou J, He J, Deng Y, Liu X, Wang C, Yang S, Chen Q, Liu L, Zhang G, Wei Y, Peng Y. Targeting Pin1 by inhibitor API-1 regulates microRNA biogenesis and suppresses hepatocellular carcinoma development. Hepatology 2018; doi; 10.1002/hep.29819.

69. Zhang R, Cao Y, Bai L, Zhu C, Li R, He H, Liu Y, Wu K, Liu F, Wu J. The collagen triple helix repeat containing 1 facilitates hepatitis $\mathrm{B}$ virus-associated hepatocellular carcinoma progression by regulating multiple cellular factors and signal cascades. Mol Carcinog 2015;54:1554-66.

70. Zhang Y, Wei Y, Li X, Liang X, Wang L, Song J, Zhang X, Zhang C, Niu J, Zhang P, Ren Z, Tang B. microRNA-874 suppresses tumor proliferation and metastasis in hepatocellular carcinoma by targeting the DOR/EGFR/ERK pathway. Cell Death Dis 2018;9:130.

71. Pinna F, Bissinger M, Beuke K, Huber N, Longerich T, Kummer U, Schirmacher P, Sahle S, Breuhahn K. A20/TNFAIP3 discriminates tumor necrosis factor (TNF)-induced NF-KB from JNK pathway activation in hepatocytes. Front Physiol 2017;8:610.

72. Stebbins J, De S, Machleidt T, Becattini B, Vazquez J, Kuntzen C, Chen L, Cellitti J, Riel-Mehan M, Emdadi A, Solinas G, Karin M, Pellecchia M. Identification of a new JNK inhibitor targeting the JNK-JIP interaction site. Proc Natl Acad Sci U S A 2008;105:16809-13.

73. Nagata H, Hatano E, Tada M, Murata M, Kitamura K, Asechi H, Narita M, Yanagida A, Tamaki N, Yagi S, Ikai I, Matsuzaki K, Uemoto $\mathrm{S}$. Inhibition of c-Jun NH2-terminal kinase switches Smad3 signaling from oncogenesis to tumor- suppression in rat hepatocellular carcinoma. Hepatology 2009;49:1944-53.

74. Wu H, Tang X, Liu H, Mao X, Wang Y. Both classic Gs-cAMP/PKA/CREB and alternative Gs-cAMP/PKA/p38B/CREB signal pathways mediate exenatide-stimulated expression of M2 microglial markers. J Neuroimmunol 2018;316:17-22.

75. Yang S, Dong S, Qu X, Zhong X, Zhang Q. Clinical significance of Wip1 overexpression and its association with the p38MAPK/p53/ p16 pathway in NSCLC. Mol Med Rep 2017;15:719-23.

76. Rudalska R, Dauch D, Longerich T, McJunkin K, Wuestefeld T, Kang T-W, Hohmeyer A, Pesic M, Leibold J, Von Thun A. In vivo RNAi screening identifies a mechanism of sorafenib resistance in liver cancer. Nat Med 2014;20:1138.

77. Verma A, Singh D, Anwar F, Bhatt P, Al-Abbasi F, Kumar V. Triterpenoids principle of Wedelia calendulacea attenuated diethynitrosamine-induced hepatocellular carcinoma via down-regulating oxidative stress, inflammation and pathology via NF-kB pathway. Inflammopharmacology 2018;26:133-46.

78. Dai W, Wu J, Zhang S, Shi B, Xu X, Wang D, Wang J. Genes directly regulated by NF-кB in human hepatocellular carcinoma HepG2. Int J Biochem Cell Biol 2017;89:157-70.

79. Sghaier I, Mouelhi L, Rabia N, Alsaleh B, Ghazoueni E, Almawi W, Loueslati B. Genetic variants in IL-6 and IL-10 genes and susceptibility to hepatocellular carcinoma in HCV infected patients. Cytokine 2017;89:62-7.

80. Marquardt J, Gomez-Quiroz L, Arreguin Camacho L, Pinna F, Lee Y, Kitade M, Domínguez M, Castven D, Breuhahn K, Conner E, Galle P, Andersen J, Factor V, Thorgeirsson S. Curcumin effectively inhibits oncogenic NF- $\mathrm{BB}$ signaling and restrains stemness features in liver cancer. J Hepatol 2015;63:661-9.

81. Ren L, Li Z, Dai C, Zhao D, Wang Y, Ma C, Liu C. Chrysophanol inhibits proliferation and induces apoptosis through NF- $\mathrm{BB} / \mathrm{cyclin}$ D1 and NF-אB/Bcl-2 signaling cascade in breast cancer cell lines. Mol Med Rep 2018;17:4376-82.

82. Liang J, Dou Y, Wu X, Li H, Wu J, Huang Q, Luo D, Yi T, Liu Y, Su Z, Chen J. Protective effect of patchoulene epoxide against ethanol-induced gastric ulcer in rats: influence on oxidative stress, inflammation and apoptosis. Chem Biol Interact 2018;283:30-7.

83. Tsai J, Pan P, Hsu F. Regorafenib induces extrinsic and intrinsic apoptosis through inhibition of ERK/NF-kB activation in hepatocellular carcinoma cells. Oncol Rep 2017;37:1036-44.

84. Yu X, Lan P, Hou X, Han Q, Lu N, Li T, Jiao C, Zhang J, Zhang C, Tian Z. HBV inhibits LPS-induced NLRP3 inflammasome activation and IL-1 $\beta$ production via suppressing the NF-KB pathway and ROS production. J Hepatol 2017;66:693-702.

85. Best B, Moran P, Ren B. VEGF/PKD-1 signaling mediates arteriogenic gene expression and angiogenic responses in reversible human microvascular endothelial cells with extended lifespan. Mol Cell Biochem 2018; doi: 10.1007/s11010-018-3286-Z.

86. Han J, Ma Z, Gao P, Lu Z, Liu H, Gao L, Lu W, Ju X, Lv F, Zhao H, Bie X. The antibacterial activity of LI-F type peptide against methicillin-resistant Staphylococcus aureus (MRSA) in vitro and inhibition of infections in murine scalded epidermis. Appl Microbiol Biotechnol 2018;102:2301-11.

87. Choi S, Han H, Kim W, Song T, Choi S. VEGF overexpression predicts poor survival in hepatocellular carcinoma. Open Med (Wars) 2017; 12:430-9.

88. Li X, Zhang D, Guan S, Ye W, Liu L, Lou L. Efficacy of anti-VEGF agents in the treatment of elderly hepatocellular carcinoma: a systematic review. Oncotarget 2017;8:93179-85. 
89. Darnell JE Jr, Kerr IM, Stark GR. Jak-STAT pathways and transcriptional activation in response to IFNs and other extracellular signaling proteins. Science 1994;264:1415-21.

90. Wang S, Sun Y. The IL-6/JAK/STAT3 pathway: potential therapeutic strategies in treating colorectal cancer (Review). Int J Oncol 2014;44:1032-40.

91. Zheng Y, Li X, Zhao H, Zhao J. Effect of matrine and oxymatrine on proliferation and expression of Stat3 and Stat5 in SMMC-7721 cell line. Zhongguo Zhong Yao Za Zhi 2008;33:2234-7. (in Chinese)

92. Wonganan O, He Y, Shen X, Wongkrajang K, Suksamrarn A, Zhang G, Wang F. 6-Hydroxy-3-O-methyl-kaempferol 6-O-glucopyranoside potentiates the anti-proliferative effect of interferon $\alpha / \beta$ by promoting activation of the JAK/STAT signaling by inhibiting SOCS3 in hepatocellular carcinoma cells. Toxicol Appl Pharmacol 2017;336:31-9.

93. Ilamathi M, Prabu P, Ayyappa K, Sivaramakrishnan V. Artesunate obliterates experimental hepatocellular carcinoma in rats through suppression of IL-6-JAK-STAT signalling. Biomed Pharmacother 2016;82:72-9.

94. Zhou G, Yi Y, Jin L, Lin W, Fang P, Lin X, Zheng Y, Pan C. The protective effect of juglanin on fructose-induced hepatitis by inhibiting inflammation and apoptosis through TLR4 and JAK2/STAT3 signaling pathways in fructose-fed rats. Biomed Pharmacother 2016;81:318-28.

95. Wang B, Liu T, Wu J, Luo S, Chen R, Lu L, Xu M. STAT3 aggravates TGF- $\beta 1$-induced hepatic epithelial-to-mesenchymal transition and migration. Biomed Pharmacother 2017;98:214-21.

96. Sihver W, Pietzsch J, Krause M, Baumann M, Steinbach J, Pietzsch H. Radiolabeled cetuximab conjugates for EGFR targeted cancer diagnostics and therapy. Pharmaceuticals (Basel) 2014;7:311-38.

97. Tan X, Lambert P, Rapraeger A, Anderson R. Stress-induced EGFR trafficking: mechanisms, functions, and therapeutic implications. Trends Cell Biol 2016;26:352-66.

98. Dang Z, Shangguan J, Zhang C, Hu P, Ren Y, Lv Z, Xiang H, Wang X. Loss of protocadherin-17 (PCDH-17) promotes metastasis and invasion through hyperactivation of EGFR/MEK/ERK signaling pathway in hepatocellular carcinoma. Tumour Biol 2016;37:2527-35.

99. Wang R, Chen L, Chen H, Hu L, Li L, Sun H, Jiang F, Zhao J, Liu G, Tang J, Chen C, Yang Y, Chang Y, Liu H, Zhang J, Yang Y, Huang G, Shen F, Wu M, Zhou W, Wang H. MUC15 inhibits dimerization of EGFR and PI3K-AKT signaling and is associated with aggressive hepatocellular carcinomas in patients. Gastroenterology 2013;145:1436-48.e1-12.

100. Li R, Yanjiao G, Wubin H, Yue W, Jianhua H, Huachuan Z, Rongjian S, Zhidong L. Secreted GRP78 activates EGFR-SRC-STAT3 signaling and confers the resistance to sorafeinib in HCC cells. Oncotarget 2017;8:19354-64.

101. Chen L, Fu W, Zheng L, Wang Y, Liang G. Recent progress in the discovery of myeloid differentiation 2 (MD2) modulators for inflammatory diseases. Drug Discov Today 2018;23:1187-202.

102. Uthaya Kumar D, Chen C, Liu J, Feldman D, Sher L, French S, DiNorcia J, French S, Naini B, Junrungsee S, Agopian V, Zarrinpar A, Machida K. TLR4 signaling via NANOG cooperates with STAT3 to activate Twist1 and promote formation of tumor-initiating stem-like cells in livers of mice. Gastroenterology 2016;150:707-19.

103. Wen J, Zhu F, Chen W, Jiang L, Chen J, Hu Z, Huang Y, Zhou Z, Wang G, Lin H, Zhou S. Oxymatrine improves intestinal epithelial barrier function involving NF-אB-mediated signaling pathway in CCl4-induced cirrhotic rats. PLoS One 2014;9:e106082.

104. Miyazaki M, Kanto T, Inoue M, Itose I, Miyatake H, Sakakibara M, Yakushijin T, Kakita N, Hiramatsu N, Takehara T, Kasahara A, Hayashi N. Impaired cytokine response in myeloid dendritic cells in chronic hepatitis C virus infection regardless of enhanced expression of Toll-like receptors and retinoic acid inducible gene-I. J Med Virol 2008;80:980-8.

105. Liu M, Xu Y, Han X, Yin L, Xu L, Qi Y, Zhao Y, Liu K, Peng J. Dioscin alleviates alcoholic liver fibrosis by attenuating hepatic stellate cell activation via the TLR4/MyD88/NF-אB signaling pathway. Sci Rep 2015;5:18038.

106. Heger M, van Golen R, Broekgaarden M, Michel M. The molecular basis for the pharmacokinetics and pharmacodynamics of curcumin and its metabolites in relation to cancer. Pharmacol Rev 2014;66:222-307.

107. Kadasa N, Abdallah H, Afifi M, Gowayed S. Hepatoprotective effects of curcumin against diethyl nitrosamine induced hepatotoxicity in albino rats. Asian Pac J Cancer Prev 2015;16:103-8.

108. El-Houseini M, El-Agoza I, Sakr M, El-Malky G. Novel protective role of curcumin and taurine combination against experimental hepatocarcinogenesis. Exp Ther Med 2017;13:29-36.

109. Halls C, Yu O. Potential for metabolic engineering of resveratrol biosynthesis. Trends Biotechnol 2008;26:77-81.

110. Yu H, Pan C, Zhao S, Wang Z, Zhang H, Wu W. Resveratrol inhibits tumor necrosis factor-alpha-mediated matrix metalloproteinase-9 expression and invasion of human hepatocellular carcinoma cells. Biomed Pharmacother 2008;62:366-72.

111. Uchida Y, Yamazaki H, Watanabe S, Hayakawa K, Meng Y, Hiramatsu N, Kasai A, Yamauchi K, Yao J, Kitamura M. Enhancement of NF-kappaB activity by resveratrol in cytokine-exposed mesangial cells. Clin Exp Immunol 2005;142:76-83.

112. Chai R, Fu H, Zheng Z, Liu T, Ji S, Li G. Resveratrol inhibits proliferation and migration through SIRT1 mediated post-translational modification of PI3K/AKT signaling in hepatocellular carcinoma cells. Mol Med Rep 2017;16:8037-44.

113. Piotrowska H, Kujawska M, Nowicki M, Petzke E, Ignatowicz E, Krajka-Kuźniak V, Zawierucha P, Wierzchowski M, Murias M, Jodynis-Liebert J. Effect of resveratrol analogue, DMU-212, on antioxidant status and apoptosis-related genes in rat model of hepatocarcinogenesis. Hum Exp Toxicol 2017;36:160-75.

114. Zhang Z, Zhao S, Yao Z, Wang L, Shao J, Chen A, Zhang F, Zheng S. Autophagy regulates turnover of lipid droplets via ROSdependent Rab25 activation in hepatic stellate cell. Redox Biol 2017;11:322-34.

115. Zaki S, Ahmed E, Motawie A, Abdel Fattah S. N-acetylcysteine versus progesterone on the cisplatin-induced peripheral neurotoxicity. Folia Morphol (Warsz) 2018;77:234-45.

116. Cheng B, Anand P, Kuang A, Akhtar F, Scofield V. N-acetylcysteine in combination with IGF-1 enhances neuroprotection against proteasome dysfunction-induced neurotoxicity in SH-SY5Y cells. Parkinsons Dis 2016;2016:6564212. 
117. Lima K, Krause G, Schuster A, Catarina A, Basso B, De Mesquita F, Pedrazza L, Marczak E, Martha B, Nunes F, Chiela E, Jaeger N, Thomé M, Haute G, Dias H, Donadio M, De Oliveira J. Gallic acid reduces cell growth by induction of apoptosis and reduction of IL-8 in HepG2 cells. Biomed Pharmacother 2016;84:1282-90.

118. Sun G, Zhang S, Xie Y, Zhang Z, Zhao W. Gallic acid as a selective anticancer agent that induces apoptosis in SMMC-7721 human hepatocellular carcinoma cells. Oncol Lett 2016;11:150-8.

119. Song M, Kim Y, Song M, Choi H, Park Y, Ryu J. Polycyclic aromatic hydrocarbons induce migration in human hepatocellular carcinoma cells (HepG2) through reactive oxygen species-mediated p38 MAPK signal transduction. Cancer Sci 2011;102:1636-44.

120. Bie B, Sun J, Li J, Guo Y, Jiang W, Huang C, Yang J, Li Z. Baicalein, a natural anti-cancer compound, alters microRNA expression profiles in Bel-7402 human hepatocellular carcinoma cells. Cell Physiol Biochem 2017;41:1519-31.

121. Gong W, Zhao Z, Liu B, Lu L, Dong J. Exploring the chemopreventive properties and perspectives of baicalin and its aglycone baicalein in solid tumors. Eur J Med Chem 2017;126:844-52.

122. Igbe I, Shen X, Jiao W, Qiang Z, Deng T, Li S, Liu W, Liu H, Zhang G, Wang F. Dietary quercetin potentiates the antiproliferative effect of interferon- $\alpha$ in hepatocellular carcinoma cells through activation of JAK/STAT pathway signaling by inhibition of SHP2 phosphatase. Oncotarget 2017;8:113734-48.

123. Ren K, Li Y, Wu G, Ren J, Lu H, Li Z, Han X. Quercetin nanoparticles display antitumor activity via proliferation inhibition and apoptosis induction in liver cancer cells. Int J Oncol 2017;50:1299-311.

124. Ma Y, Wang J, Liu L, Zhu H, Chen X, Pan S, Sun X, Jiang H. Genistein potentiates the effect of arsenic trioxide against human hepatocellular carcinoma: role of Akt and nuclear factor-kB. Cancer Lett 2011;301:75-84.

125. Babu L, Perumal S, Balasubramanian M. Myrtenal, a natural monoterpene, down-regulates TNF- $\alpha$ expression and suppresses carcinogen-induced hepatocellular carcinoma in rats. Mol Cell Biochem 2012;369:183-93.

126. Zaghloul R, Elsherbiny N, Kenawy H, El-Karef A, Eissa L, El-Shishtawy M. Hepatoprotective effect of hesperidin in hepatocellular carcinoma: involvement of Wnt signaling pathways. Life Sci 2017;185:114-25.

127. Lin X, Kong L, Huang C, Ma T, Meng X, He Y, Wang Q, Li J. Hesperetin derivative-7 inhibits PDGF-BB-induced hepatic stellate cell activation and proliferation by targeting Wnt/ $\beta$-catenin pathway. Int Immunopharmacol 2015;25:311-20.

128. Zhang J, Song J, Wu D, Wang J, Dong W. Hesperetin induces the apoptosis of hepatocellular carcinoma cells via mitochondrial pathway mediated by the increased intracellular reactive oxygen species, ATP and calcium. Med Oncol 2015;32:101.

129. Lee K, Yeh M, Kao S, Hung C, Liu C, Huang Y, Yeh C. The inhibitory effect of hesperidin on tumor cell invasiveness occurs via suppression of activator protein 1 and nuclear factor-kappaB in human hepatocellular carcinoma cells. Toxicol Lett 2010;194:42-9.

130. Xu X, Zhang K, Zhao L, Li C, Bu W, Shen Y, Gu Z, Chang B, Zheng C, Lin C, Sun H, Yang B. Aspirin-based carbon dots, a good biocompatibility of material applied for bioimaging and anti-inflammation. ACS Appl Mater Interfaces 2016;8:32706-16.

131. Abdelmonsif D, Sultan A, El-Hadidy W, Abdallah D. Targeting AMPK, mTOR and $\beta$-catenin by combined metformin and aspirin therapy in HCC: an appraisal in Egyptian HCC patients. Mol Diagn Ther 2018;22:115-27.

132. Xia H, Hui KM. Emergence of aspirin as a promising chemopreventive and chemotherapeutic agent for liver cancer. Cell Death Dis 2017;8:e3112.

133. Márquez-Rosado L, Trejo-Solís M, García-Cuéllar C, Villa-Treviño S. Celecoxib, a cyclooxygenase-2 inhibitor, prevents induction of liver preneoplastic lesions in rats. J Hepatol 2005;43:653-60.

134. Behari J, Zeng G, Otruba W, Thompson M, Muller P, Micsenyi A, Sekhon S, Leoni L, Monga S. R-Etodolac decreases beta-catenin levels along with survival and proliferation of hepatoma cells. J Hepatol 2007;46:849-57.

135. Nagahara T, Okano J, Fujise Y, Abe R, Murawaki Y. Preventive effect of JTE-522, a selective cyclooxygenase-2 inhibitor, on DENinduced hepatocarcinogenesis in rats. Biomed Pharmacother 2010;64:319-26.

136. Yin G, Tu K, Han S, Wang J, Liu Q, Yao Y. Downregulation of HSP70 gene expression and apoptosis in human hepatocellular carcinoma SMMC-7721 cells induced by nimesulide in vitro. Xi Bao Yu Fen Zi Mian Yi Xue Za Zhi 2012;28:933-6. (in Chinese)

137. Pei Q, Jiang P, Yang M, Qian X, Liu J, Kim S. Roxithromycin inhibits VEGF-induced human airway smooth muscle cell proliferation: Opportunities for the treatment of asthma. Exp Cell Res 2016;347:378-84.

138. Ding D, Huang H, Jiang W, Yu W, Zhu H, Liu J, Saiyin H, Wu J, Huang H, Jiang S, Yu L. Reticulocalbin-2 enhances hepatocellular carcinoma proliferation via modulating the EGFR-ERK pathway. Oncogene 2017;36:6691-700.

139. Chen L, Zhou D, Liu Z, Huang X, Liu Q, Kang Y, Chen Z, Guo Y, Zhu H, Sun C. Combination of gemcitabine and erlotinib inhibits recurrent pancreatic cancer growth in mice via the JAK-STAT pathway. Oncol Rep 2018;39:1081-9.

140. Kaseb A, Morris J, Iwasaki M, Al-Shamsi H, Raghav K, Girard L, Cheung S, Nguyen V, Elsayes K, Xiao L, Abdel-Wahab R, Shalaby A, Hassan M, Hassabo H, Wolff R, Yao J. Phase II trial of bevacizumab and erlotinib as a second-line therapy for advanced hepatocellular carcinoma. Onco Targets Ther 2016;9:773-80.

141. Finn R. Emerging targeted strategies in advanced hepatocellular carcinoma. Semin Liver Dis 2013;33 Suppl 1:S11-9.

142. Wu Z, Galmiche A, Liu J, Stadler N, Wendum D, Segal-Bendirdjian E, Paradis V, Forgez P. Neurotensin regulation induces overexpression and activation of EGFR in HCC and restores response to erlotinib and sorafenib. Cancer Lett 2017;388:73-84.

143. Villanueva A, Luedde T. The transition from inflammation to cancer in the liver. Clinical Liver Disease 2016;8:89-93.

144. El-Khoueiry AB, Sangro B, Yau T, Crocenzi TS, Kudo M, Hsu C, Kim TY, Choo SP, Trojan J, Welling 3rd TH. Nivolumab in patients with advanced hepatocellular carcinoma (CheckMate 040): an open-label, non-comparative, phase 1/2 dose escalation and expansion trial. Lancet 2017;389:2492-502. 